\title{
Patient Satisfaction with Healthcare at a Tertiary Hospital in Northern Malawi: Results from a Triangulated Cross-sectional Survey
}

Frank Watson Sinyiza

Mzuzu Central Hospital

Paul Uchizi Kaseka

Mzuzu Central Hospital

Master Rodgers Chisale

Mzuzu University

Chikondi Sharon Chimbatata

Mzuzu Central Hospital

Balwani Chingatichifwe Mbakaya

University of Livingstonia

Pocha Samuel Kamudumuli

University of Maryland Global Initiative Corporation

Tsung-Shu Joseph Wu

Luke International

Alfred Bornwell Kayira ( $\square$ kayiraalfred@gmail.com)

Mzuzu Central Hospital

Research Article

Keywords: Patient satisfaction, Client satisfaction, Quality of care, Healthcare

Posted Date: November 18th, 2021

DOI: https://doi.org/10.21203/rs.3.rs-1076970/v1

License: @ (i) This work is licensed under a Creative Commons Attribution 4.0 International License. Read Full License 


\section{Abstract}

\section{Background}

In 2016 the Malawi government embarked on several interrelated health sector reforms aimed at improving the quality of health services at all levels of care and attain Universal Health Coverage by 2030. Patient satisfaction with services is an important proxy measure of quality. We assessed patient satisfaction at a tertiary hospital in Northern Malawi to understand the current state in the country.

\section{Methods}

We conducted exit interviews with patients aged 18 years and above using a 28 statement interviewer administered questionnaire. Patients were asked to express their level of agreement to the statements on a five-point Likert scale - strongly disagree to strongly agree, corresponding to scores of 1 to 5 . Overall patient satisfaction was calculated by summing up the scores and diving the sum by the number of statements. Scores $>3$ constituted satisfaction while scores $\leq 3$ constituted dissatisfaction. Patient self-rated satisfaction was determined from a single statement that asked patients to rate their satisfaction with services on a five-point Likert scale. We also solicited inputs from patients on aspects of hospital care that needed improvement. Responses were reviewed and grouped into themes. Recurring themes are presented according to frequencies.

\section{Results}

Overall patient satisfaction was $8.4 \%$ (95\% Cl: $5.2 \%$ - 12.9\%). Patient self-rated satisfaction was $8.9 \%$ (95\% $\mathrm{Cl}: 5.5 \%$ - $13.4 \%)$. Patients raised six major issues that dampened their healthcare seeking experience including health workers reporting late to work, doctors not listening to patients concerns and neither examining them properly nor explaining the diagnosis, shortage of medicines, diagnostics and medical equipment, unprofessional conduct of health workers, poor sanitation and cleanliness, and health workers behaviour of favouring or priotising their relatives and friends over other patients.

\section{Conclusion}

We found very low levels of patient satisfaction, suggesting that quality of services in the public health sector is still low. It is therefore critical to accelerate and innovate the Ministry of Health's quality improvement initiatives to attain Malawi's health goals.

\section{Introduction}

As a signatory to the Sustainable Development Goals (SDGs) Malawi aspires to achieve Universal Health Coverage (UHC) by 2030 (1). However, a situation analysis of the health sector in Malawi identified low quality of care as a major setback to achieving UHC and improving population health outcomes (2). Based on recommendations of this report the Malawi government has since 2016 been undertaking several interrelated health sector reforms aimed at, among others, improving the quality of health services at all levels of care (1). These initiatives are meant to improve, increase, promote or strengthen leadership, governance and social accountability; human resource capacity; clinical practices; client safety; people-centered care; supply chain systems and research, monitoring and evaluation capacity (1). In 2018, the Ministry of Health and Population (MOHP) designated patient or client satisfaction with services as one of the main indicators for monitoring improvements in the quality of services in public health facilities in Malawi, and encouraged the conduct of patient satisfaction surveys disaggregated by service type and facility type every two years (3). The target is that by 2022 at least $80 \%$ of patients or clients should report being satisfied or very satisfied with the health services provided in its health facilities (3).

Patient satisfaction, defined as the congruence between patient expectations of optimal care and the perception of the actual care received (4), is not without limitations when used as an indicator for the quality of care. According to the Donabedian quality of care model, healthcare quality encompasses the technical competencies of the providers as well as the interpersonal process through which that care is provided (5). Technical quality of care is judged against the best in practice which is known or believed to produce the greatest improvements in health (5). But Avedis Donabedian argues that due to limitation in medical knowledge most patients cannot competently assess the technical skills of their provider, and may therefore have low or no expectations on the technical quality of care (5). Arah et al found that higher self-reported technical quality of care in diabetes was not always associated with better experiences and ratings (6). Therefore, their satisfaction scores may only indicate the interpersonal skills (privacy, confidentiality, concern, compassion, honesty, tact, sensitivity, communication, patient involvement in decision making) of the provider and good healthcare outcomes (effective treatment with no preventable complications). But even if the healthcare outcome is not good (i.e. treatment did not bring about any health improvements or lead to even more catastrophic consequences) the quality of care given will still be judged as good if it conformed to best practice permitted by the science and technology of the day. Therefore satisfaction or dissatisfaction with care does not necessarily equate to receipt of good or bad quality of technical care. As such, some scholars discourage the use of patient satisfaction surveys as a measure of overall quality of care (7).

However, in recent decades, there has been a major shift in healthcare practice from the traditional way of defining quality of healthcare in terms of the technical standards to one that includes patient's perception and judgement about the services received (8). Patient perception about the quality of and trust in the healthcare services received has a huge bearing on their continued utilisation of healthcare and compliance with care regimens and suggested lifestyle modifications, which in turn affects treatment outcomes (9). Donabedian, in his model of quality of care, corroborates the importance good interpersonal relationship between the provider and the patient because the interpersonal process serves as the vehicle by which technical care is implemented and on which its success depends (5). And beyond technical and interpersonal quality aspects of care, patient satisfaction is also influenced by availability and accessibility of healthcare providers, medicines and diagnostic services; cost of services; and hospital infrastructure (10)(11). Furthermore, studies have reported a direct link between quality of services and patient satisfaction with the services (12)(13)(14), justifying the use of patient satisfaction as a dependable measure of quality of care and therefore an important component of health system performance improvement. Globally, in spite of limitations and debates surrounding it, patient satisfaction is still widely used and accepted as a reliable measure of quality of healthcare services. Justified by these 
strengths and responding to the MOHP's call for regular patient satisfaction surveys as a way of obtaining important feedback from clients and patients on the quality of services in public health facilities we assessed patient satisfaction with healthcare at a tertiary hospital in Northern Malawi.

\section{Methods}

\section{Study design and setting}

This was a descriptive cross-sectional study. It was carried out at Mzuzu Central Hospital (MCH) between January, 2021 and February, 2021 during the second surge of COVID-19 cases in the country. MCH is tertiary hospital located in Mzuzu City, Northern Malawi. It is a 410 bed capacity hospital and serves as the referral facility for six health districts that constitute the Northern Region and serving a population of 2,289,780 people (15). Ideally the hospital provides specialist health services at the regional level. In practice, however, around $70 \%$ of the services it provides are either primary or secondary (16). This is mainly due to unavailability of proper primary and secondary level health facilities in Mzuzu city and the surrounding areas and lack of a gate-keeping system (16). Daily bed occupancy is at 410 and about 50 inpatients are discharged from hospital daily. Hospital records showed that the facility also treats about 500 patients daily on an outpatient basis.

\section{Data collection, management and analysis}

We conducted exit interviews with patients aged 18 years and above shortly after having been discharged from hospital or (in the case of outpatients) after they were through with consultation and received treatment. Interviewer administered structured questionnaire was used to collect data from patients. We engaged non-Mzuzu Central Hospital staff as interviewers to encourage free expression by patients. Interviewers had professional training in nursing and medicine. They were dressed in civilian clothes and interviews were done at a private place, away from identifiable hospital staff. Interviewers were trained in data collection tools and procedures before embarking on the exercise.

The questionnaire consisted of 28 statements grouped into six domains of care: (1) Communication (four statements), (2) Relational conduct (five statements), (3) Technical skills/competence (five statements), (4) Personal qualities/attributes (three statements), (5) Availability and accessibility (six statements), and (6) Hospital environment (five statements). Statements under communication domain solicited information from patients on whether healthcare providers provided adequate and patient tailored information on the investigations being done and eventual diagnosis, and adequately addressed patient concerns. Relation conduct domain comprised statements seeking information on whether patients were treated with respect by providers and were adequately involved in decision making. Statements under technical skills domain gathered information on whether providers demonstrated a masterly of their job. The personal attributes domain statements probed whether patients were treated courteously, and with privacy and empathy by providers.

Statements under availability and accessibility thematic area solicited information on whether doctors were readily available and accessible to patients at the hospital and whether medicines, diagnostic services and functional medical equipment were also available. The hospital environment domain asked patients to rate the adequacy, cleanliness and tidiness of sanitary facilities and hospital surroundings as well as the state of hospital infrastructure and room space.

Patients were asked to indicate their level of agreement to the statements on a five-point Likert scale: 1. Strongly disagree, 2. Disagree, 3. Not sure, 4. Agree, and 5. Strongly agree. The questionnaire contained a mix of statements expressing both positive and negative sentiments in a random order to minimize acquiescence bias. Together, the 28 statements provided a composite measure of satisfaction which we call Overall satisfaction. The questionnaire further contained a statement "On the overall, I am satisfied with the services I have received". Patients were asked to express their level of agreement to a statement with responses on a five-point Likert scale, from 1.Strongly disagree to 5 .Strongly agree. This statement solicited patients' own subjective assessment of their healthcare seeking experience, herein referred to as self-rated satisfaction. The questionnaire also contained an open-ended question asking patients to mention any areas or aspects of care that needed improvement at the hospital. This question solicited inputs from patients so as to understand their perspective of quality healthcare

Data were entered in Microsoft excel 2016, cleaned and then imported into STATA V.13.0 (StataCorp) for analysis. But before any analysis could begin responses to all negatively framed statements were first re-coded so that all scores $(1,2,3,4,5$ corresponding to strongly disagree, disagree, not sure, agree and strongly agree) were in the same sense (i.e. the higher the score the higher the level of satisfaction). Overall patient satisfaction was calculated by adding up individual satisfaction scores across the six domains of care to get an overall score and then dividing this overall score by the total number of statements in the six domains. This calculation brought the overall scores back into the scale of 1 to 5 . An overall score of more than 3 was treated as 'Satisfied' while an overall score of 3 or less was treated as 'Unsatisfied'. This analysis was repeated for each domain to calculate domain specific overall satisfaction.

Self-rated satisfaction was calculated from patients' responses to a single statement "On the overall, I am satisfied with the services I have received". Responses 'Strongly agree' and 'Agree' constituted satisfaction with the services received while 'Not sure', 'Disagree' and 'Strongly disagree' constituted dissatisfaction. The response 'Not sure' was categorized on the dissatisfaction side because we felt that that was patients' polite way of saying the services were not good. We believe if patients were happy with the services they received they would not hesitate to say so. Patients' responses to an open ended question were reviewed by investigators and grouped into recurring themes.

Descriptive statistics were performed to summarize patient characteristics. Overall patient satisfaction was the main outcome of analysis. A Chi square $\left(\chi^{2}\right)$ test of independence was used to test for associations between overall satisfaction and independent variables of interest. A $\chi^{2}$ test was performed for all cross tabulations where the sample size ( $n$ ) was greater than the number of cells multiplied by 5 and where the expected value in $80 \%$ of the contingency cells was greater than 5 and no cell had the expected value of less than 3 . Where this condition was not met a Fisher's exact test was performed instead. A p-value of 0.05 or less was considered statistically significant.

\section{Results}


A total of 225 patients (93 inpatients and 132 outpatients) participated in the survey, $126(56.0 \%)$ of whom were female. Patients aged $20-29$ years constituted the majority (38.7\%) of the study participants. Half (50\%) of the patients had secondary level education. The majority of patients (77.8\%) were residents of the Northern region while $58.7 \%$ of all patients were treated as outpatients. Most patients (44.4\%) were seen at the general outpatient department (Table 1).

Patient satisfaction with healthcare ranged from $4.9 \%$ for health worker attributes to $27.1 \%$ for availability and accessibility of health workers and health services. Overall satisfaction was $8.4 \%$ (95\% Cl: 5.2\% - 12.9\%) while patient self-rated satisfaction was $8.9 \%$ (95\% Cl: $5.5 \%$ - 13.4\%) (Table1).

Table1. Demographic characteristics of patients and satisfaction with healthcare at a tertiary hospital in Northern Malawi 


\begin{tabular}{|c|c|c|}
\hline Variable & Categories & n $(\% ; 95 \% \mathrm{Cl})$ \\
\hline \multirow[t]{2}{*}{ Sex } & Male & $99(44.0)$ \\
\hline & Female & $126(56.0)$ \\
\hline \multirow[t]{6}{*}{ Age (years) } & $<20$ & $15(6.7)$ \\
\hline & $20-29$ & $87(38.7)$ \\
\hline & $30-39$ & $56(24.9)$ \\
\hline & $40-49$ & $33(14.7)$ \\
\hline & $50-59$ & $15(6.7)$ \\
\hline & $\geq 60$ & $19(8.4)$ \\
\hline \multirow[t]{4}{*}{ Education } & None & $8(3.6)$ \\
\hline & Primary & $68(30.2)$ \\
\hline & Secondary & $113(50.2)$ \\
\hline & Tertiary & $36(16.0)$ \\
\hline \multirow[t]{5}{*}{ Marital status } & Married & $150(66.7)$ \\
\hline & Single & $56(24.9)$ \\
\hline & Divorced & $9(4.0)$ \\
\hline & Widowed & $9(4.0)$ \\
\hline & Other & $1(0.4)$ \\
\hline \multirow[t]{3}{*}{ Religion } & Christian & $217(96.4)$ \\
\hline & Muslim & $7(3.1)$ \\
\hline & Other & $1(0.4)$ \\
\hline \multirow[t]{3}{*}{ Region } & Northern & $175(77.8)$ \\
\hline & Central & $24(10.7)$ \\
\hline & Southern & $26(11.6)$ \\
\hline \multirow[t]{2}{*}{ Visit type } & Outpatient & $132(58.7)$ \\
\hline & Inpatient & $93(41.3)$ \\
\hline \multirow[t]{7}{*}{ Department consulted } & General OPD & $100(44.4)$ \\
\hline & Obstetrics \& Gynaecology & $46(20.4)$ \\
\hline & Medical & $37(16.4)$ \\
\hline & Surgical & $22(9.8)$ \\
\hline & Dental & $11(4.9)$ \\
\hline & Ophthalmology & $5(2.2)$ \\
\hline & ART clinic & $4(1.8)$ \\
\hline \multicolumn{3}{|l|}{ Patient satisfaction } \\
\hline \multirow[t]{2}{*}{ Communication } & Satisfied & $40(17.8)$ \\
\hline & Unsatisfied & $185(82.2)$ \\
\hline \multirow[t]{2}{*}{ Rational conduct } & Satisfied & $20(8.9)$ \\
\hline & Unsatisfied & $205(91.1)$ \\
\hline \multirow[t]{2}{*}{ Technical competence } & Satisfied & $29(12.9)$ \\
\hline & Unsatisfied & $196(87.1)$ \\
\hline \multirow[t]{2}{*}{ Personal attributes } & Satisfied & $11(4.9)$ \\
\hline & Unsatisfied & $214(95.1)$ \\
\hline \multirow[t]{2}{*}{ Availability and accessibility } & Satisfied & $61(27.1)$ \\
\hline & Unsatisfied & $164(72.9)$ \\
\hline
\end{tabular}

Page 5/12 


\begin{tabular}{lll} 
Sanitation and cleanliness & Satisfied & $17(7.6)$ \\
\hline & Unsatisfied & $207(92.40$ \\
\hline Overall satisfaction & Satisfied & $19(8.4 ; 5.2-12.9)$ \\
\hline \multirow{2}{*}{ Self-rated satisfaction } & Unsatisfied & $206(91.6)$ \\
\hline & Satisfied & $20(8.9 ; 5.5-13.4)$ \\
\hline & Unsatisfied & $205(91.1)$
\end{tabular}

A Chi square or Fishers's exact test was used to explore associations between overall patient satisfaction and demographic characteristics of participants and other variables. None of the variables examined had a statistically significant association with overall patient satisfaction (Table2).

Table 2. Association between demographic characteristics and overall patient satisfaction 


\begin{tabular}{|c|c|c|c|c|}
\hline \multirow[t]{3}{*}{ Variable } & & \multicolumn{2}{|c|}{ Overall Satisfaction } & \multirow[t]{3}{*}{$\chi 2$ or Fisher's exact (P-value) } \\
\hline & & Satisfied & Unsatisfied & \\
\hline & & $\mathrm{n}(\%)$ & n (\%) & \\
\hline \multirow[t]{2}{*}{ Sex } & Male & $5(5.1)$ & $94(94.9)$ & $2.6(0.11)$ \\
\hline & Female & $14(11.1)$ & $112(88.9)$ & \\
\hline \multirow[t]{6}{*}{ Age (years) } & $<20$ & $0(0.0)$ & $15(100)$ & $\ldots(0.14)$ \\
\hline & $20-29$ & $12(13.8)$ & $75(86.2)$ & \\
\hline & $30-39$ & $2(3.6)$ & $54(96.4)$ & \\
\hline & $40-49$ & $4(12.1)$ & $29(87.9)$ & \\
\hline & $50-59$ & $1(6.7)$ & $14(93.3)$ & \\
\hline & $\geq 60$ & $0(0.0)$ & $19(100)$ & \\
\hline \multirow[t]{4}{*}{ Education } & None & $0(0.0)$ & $8(100)$ & $\ldots(0.97)$ \\
\hline & Primary & $5(7.4)$ & $63(92.6)$ & \\
\hline & Secondary & $11(9.7)$ & $102(90.3)$ & \\
\hline & Tertiary & $3(8.3)$ & $33(91.7)$ & \\
\hline \multirow[t]{5}{*}{ Marital status } & Married & $11(7.3)$ & $139(92.7)$ & $\ldots(0.53)$ \\
\hline & Single & $7(12.5)$ & $49(87.5)$ & \\
\hline & Divorced & $1(11.1)$ & $8(88.9)$ & \\
\hline & Widowed & $0(0.0)$ & $9(100)$ & \\
\hline & Other & $0(0.0)$ & $1(100)$ & \\
\hline \multirow[t]{3}{*}{ Religion } & Christian & $19(8.8)$ & $198(91.2)$ & $\ldots(1.00)$ \\
\hline & Muslim & $0(0.0)$ & $7(100)$ & \\
\hline & Other & $0(0.0)$ & $1(100)$ & \\
\hline \multirow[t]{3}{*}{ Region } & Northern & $15(8.6)$ & $160(91.4)$ & $\ldots(1.00)$ \\
\hline & Central & $2(8.3)$ & $22(91.7)$ & \\
\hline & Southern & $2(7.7)$ & $24(92.3)$ & \\
\hline \multirow[t]{2}{*}{ Visit type } & Outpatient & $14(10.6)$ & $118(89.4)$ & $1.9(0.17)$ \\
\hline & Inpatient & $5(5.4)$ & $88(94.6)$ & \\
\hline \multirow[t]{7}{*}{ Department consulted } & General OPD & $13(13.0)$ & $87(87.0)$ & $\ldots(0.26)$ \\
\hline & Obs \& Gynae & $4(8.7)$ & 42 991.3) & \\
\hline & Medical & $0(0.0)$ & $37(100)$ & \\
\hline & Surgical & $1(4.5)$ & $21(95.5)$ & \\
\hline & Dental & $1(9.1)$ & $10(90.9)$ & \\
\hline & Eye & $0(0.0)$ & $5(100)$ & \\
\hline & ART clinic & $0(0.0)$ & $4(100)$ & \\
\hline
\end{tabular}

The top six areas of improvement cited by patients are that health workers should report to work on time at $29.8 \%$ followed by a plea that doctors should listen to patients' concerns, examine them thoroughly and explain their findings and diagnosis, including the reasons for doing blood tests and other examinations at $17.8 \%$ (Table 3). "Doctors should come to work on time and examine patients properly", said a 27 year-old male when asked what he thought could have been done differently to improve his experience at the hospital. While a 35 year-old female had this to say "Doctors should pay attention to patients and examine them properly based on their complaints".

Third was an observation that the hospital should improve its stocks of essential medicines, diagnostics and medical furniture at $14.7 \%$, which was followed by an earnest call that health workers must conduct themselves professionally at $12.9 \%$ (Table 3). "Doctors should minimize chatting with colleagues and on their phones when attending to us" said a 21 year-old woman when asked what should improve at the hospital to make her experience better. Another 20 year- 
old female responded "Stock enough drugs in the pharmacy and provide more chairs on the outpatient queues so that we can observe social distance during this era of COVID-19".

On fifth position, there was a call from $6.7 \%$ of patients that hospital management have to improve cleanliness in the hospital's sanitary facilities and regularly maintain the physical infrastructure. Finally at number six, $4.0 \%$ of patients bemoaned the behaviour of some health workers who favour or prioritise their relatives and friends over other patients and pleaded that heath workers should change this discriminatory behaviour (Table 3 ). When asked what she thought should have been done differently in order to improve her experience at the hospital a 60 year old female said "improve sanitation in the toilets" while 63 year old woman said "stop prioritizing relatives and friends of health workers and treat us all equally".

Seventy two patients (32\%) contradicted their initial responses and said they were satisfied with the services they received (Table 3). When asked to mention areas that needed improvement at the hospital so as to make their experience better next time they come to seek care a 42 year old male said "I'm satisfied with the services". An 18 year old female said "The hospital should keep up the good work it is doing" while a 36 year old female said "There's improvement on abuse of patients and that should continue".

Table 3. Areas of improvement reported by patients

Area of improvement

Number of patients who mentioned

Timely reporting to work

$67(29.8)$

Doctors should listen to patients concerns, examine them properly and explain the diagnosis

$40(17.8)$

Unavailability/frequent stock outs of essential health commodities (medicines, diagnostics, medical equipment/furniture)

Professional conduct of health workers

$33(14.7)$

Sanitation and cleanliness

$29(12.9)$

$15(6.7)$

Health workers should not favour/priotise their relatives over other patients

$9(4.0)$

Provide adequate physical space to be able to observe social distancing in the wake of COVID-19

Reduce by-pass fees

$6(2.7)$

Continuity of care - maintain same doctors during the next visits

$3(1.3)$

Technical competence of health workers

Unity among health workers

$2(0.9)$

Health workers should stop soliciting/taking bribes from patients

$2(0.9)$

Availability and accessibility of doctors

Supervision and control of students on clinical placements

$1(0.40$

Satisfied with the services

$72(32.0 \%)^{\bigotimes}$

${ }^{\square}$ Of the 72 patients that said they were satisfied with the services they received 71 (98.6\%) of them were not satisfied with the care they received in our objectively measured overall satisfaction, and all of them (100\%) reported not being satisfied in their self-rated overall satisfaction. Forty two (58.3\%) of them had completed at least secondary school education

\section{Discussion}

This descriptive cross-sectional study assessed patient satisfaction with healthcare at a tertiary hospital in Northern Malawi. We assessed patient satisfaction in six domains of care (communication, rational conduct, technical competence, personal qualities, availability and accessibility, and sanitation and cleanliness) and calculated overall patient satisfaction with the care they received. We have also reported patient self-rated satisfaction with care and patient suggested areas of improvement for the hospital. To our knowledge this is the first study in Malawi to have taken a multi-pronged approach to assessing patient satisfaction and to have assessed satisfaction holistically and not focussing on a specific service or hospital department.

Patient satisfaction ranged from $4.9 \%$ with health workers' personal qualities to $27.1 \%$ with availability and accessibility of health workers and health services while overall satisfaction with medical care was $8.4 \%$ and self-rated satisfaction was $8.9 \%$. These results show that patients were not happy with the services across all the domains of care and it is not surprising therefore that overall patient satisfaction was this low $-8.4 \%$, and so was patient self-rated satisfaction at $8.9 \%$. It is reassuring to note, however, that our measured overall satisfaction was not different from patient self-rated satisfaction, giving confidence in the tool that we used to objectively assess patient satisfaction. Therefore, instituting improvements in the domains of care that we assessed may lead to increased satisfaction with care among patients.

Previous studies reported high levels of satisfaction with healthcare services in Malawi. In a study investigating client satisfaction with cervical cancer screening all women (100\%) reported that they were satisfied with the services, with $68.3 \%$ reporting being very satisfied (17). Creanga and colleagues found

Page 8/12 
patient satisfaction levels of more than $85 \%$ with perinatal healthcare (2). Ninety seven percent (97\%) of women were satisfied with reproductive health services at Gogo Chatinkha Maternity Unit in Blantyre, Malawi (19) while more than $75 \%$ of stroke patients were said to be satisfied by the care they received in four tertiary hospitals in Malawi (20).

All of the above studies have fundamental differences from our study. While we attempted to assess the hospital as a system, encompassing as many dimensions of care that might lead to patient satisfaction (or otherwise) as possible, they focused on a specific service provided by specific staff in a particular unit or department of the hospital. Taking such a narrow and focused approach one is likely to find higher levels of satisfaction. In Nigeria and Uganda studies that assessed only one aspect of care provided by the hospital or clinic, or a particular department or clinic of the hospital reported higher levels of satisfaction (91.6\% and $93.8 \%$ respectively) (21)(22).

The hospital is, however, a much broader system. In navigating such a system patients may encounter several frustrations along the way. When patients come to seek care they often interact with multiple providers with varying technical competencies and personal manners, and from multiple professional backgrounds and departments, not to mention physical and sanitary facilities. In resource constrained countries like Malawi patients are also faced with limited availability and accessibility of both health workers and essential medicines and diagnostic services. Studying patient experiences with the healthcare system from such a broader perspective one may likely find lower levels of satisfaction. In Ethiopia and Uganda studies that took a similar approach to our own and measured patient satisfaction in a similar manner found lower levels of satisfaction $(40.7 \%, 49.2 \%, 46.2$ and $50.0 \%$ respectively) with nursing care among hospitalized patients, inpatient services and outpatient services (23)(24)(25)(26). Even though our results are still far lower than these the trend is visibly apparent and the observed discrepancies could be due differences in study sites. We are, therefore, of the view that when assessing patient satisfaction with hospital care taking a holistic approach is the best way to draw out true hospital ratings from the people it serves and endeavors to serve better.

Further, this study was conducted during the peak of the second surge of COVID-19 in Malawi. COVID-19 has had significant impact on the delivery of other essential health services Sub-Saharan Africa, including Malawi. It led to shortage of human and material resources due to staff and money being redirected to tackle the epidemic (27)(28). COVID-19-related stressors such as physical exhaustion, alarming deaths of COVID-19 patients and the fear of contracting infection and subsequently passing it to family members took a huge toll on mental health of health workers (29)(30), which in turn may have affected how healthcare providers related with the very patients they had sworn to care for. Globally, COVID-19 lockdowns disrupted supply chains and lead to acute shortage of medicines and other essential health commodities in Malawi (31)(32). In addition, the global scramble for essential health commodities such as masks and other protective equipment (PPE) led to severe shortages of these items in third world countries like Malawi (33). Without appropriate and adequate PPE it was hard for health workers to maintain good provider-patient interactions and discharge their duties comfortably. A combination of these factors may have plummeted healthcare provider and hospital ratings in the eyes of the patient.

We examined the association between overall patient satisfaction and independent variables listed in Table 1 using a Chi square or Fishers's exact test as appropriate. The goal was to identify variables associated with overall patient satisfaction at $5 \%$ significance level so that these would be further assessed for the strength and nature of the relationship in a logistic regression. But none of the variables had a significant association with overall patient satisfaction and so we could not proceed with a regression analysis. There are studies which did not find significant associations between satisfaction and variables in the table as much as there are studies which reported significant associations between satisfaction and some of the variable in the table. Maseko et al found no association between client satisfaction with cervical cancer screening and age, education level or marital status(17) while Nabbuye-Sekandi and colleagues reported higher levels of satisfaction among clients with primary or secondary education compared with those that had no formal education (26). They also found greater levels of satisfaction among clients who attended certain specialized clinics (HIV treatment and research clinic) than among those who attended general outpatient clinics (26). Sharew et al reported the opposite of what Nabbuye-Sekandi et al had reported. In their study they found that patients with at least primary education were $80 \%$ less satisfied compared with those without any formal education (24). So failure by our study to find any significant associations between satisfaction and demographic variables, visit type and department or clinic consulted could mean that indeed there is no association, or simply a failure by our study to detect these associations owing to few events (only $8.4 \%$ of patients were satisfied with the care they received and therefore could not achieve adequate distribution for optimal comparison).

Patients raised various issues that dampened their healthcare seeking expereince at the hospital. Top on the list were health workers reporting late to work, that doctors do not listen to patients' concerns and that they do not take time to examine patients thoroughly and explain the findings, shortage of medicines and diagnostics, and unprofessional conduct of health workers. Five of the top six items raised by patients were already included in questionnaire we used to objectively assess patient satisfaction, giving reassuarance that the tool we used touched on issues that patients too considered important. A small proportion of patients also raised some important issues that the hospital may have to consider if it is to appeal to its catchment population. Concerns that health workers are favouring or prioritizing their relatives and friends over ordinary patients by aiding them to skip the queue, the revelation that some health workers are soliciting bribes from patients, and the need for adequate physical space so that patients can observe social distance while waiting on the queue during this COVID-19 pandemic must be looked into. None of the issues raised were related to the technical aspects care. Nonetheless, these are the things that patients are able to observe and upon which they base their evaluation of the performance of the hospital. Therefore, while aiming to improve the technical quality of care particular attention must be paid to the nontechnical aspects of it as well.

When asked to mention areas that the hospital should improve on to meet their expectations a substantial proportion of patients (32\%) had nothing specific to point a finger at other than to contradict their earlier statements and say they were satisfied with the care they had received. Of these, $98.6 \%$ were not satisfied with the care they received by our measured overall satisfaction, and all of them (100\%) reported not being satisfied in their self-rated satisfaction. Forty-two $(58.3 \%)$ of them had completed at least secondary education. This contradictory result is interesting. There could be a couple of plausible explanations why these patients contracted their earlier responses. We suspect that despite many of them having good education they still lacked knowledge on their rights with regard to healthcare, and therefore had no expectations of the quality of services they ought to receive. Without expectations it is difficult to judge the actual care received, and that is why they were not able to point out a single thing that was not right in the services they had received.

Page 9/12 


\section{Conclusions}

Patient satisfaction was very low across all the domains of care, suggesting that patients were not happy with the quality of services received. This is a strong message to policy makers and health managers to improve the quality of services and patient experience in their facilities. To stay true to its commitment of improving population health outcomes and achieve UHC by 2030 through provision of quality services the Malawi government has to step up and accelerate current initiatives meant to improve quality of services or innovate its quality improvement approaches. Furthermore, the Malawi health system has to get better prepared for future pandemics because these tend to reverse the gains made in previous years. In addition, the Malawi government and development partners should consider sensitizing citizens on their rights and responsibilities enshrined in the Malawi service charter on patients' and health service providers' rights and responsibilities so that they know what to expect from and what is expected of them during a healthcare seeking encounter. Until there is congruence between expectations of ideal care and the actual care received it will be difficult for patients to rate the services received as satisfactory or not. So even if the Malawi government is to make investments to improve quality of care and patient experience in its facilities future patient satisfaction surveys may still fail to detect changes in levels of satisfaction as patients may not be able to distinguish between optimal and suboptimal care.

\section{Abbreviations}

MOHP: Ministry of Health and Population; UHC: Universal Health Coverage; PPE: Personal Protective Equipment

\section{Declarations}

\section{Ethics approval and consent to participate}

The study was approved by Mzuzu University Research and Ethics Committee (MZUNIREC). Permission to conduct the study was also obtained from Mzuzu Central Hospital Research Committee. Written informed consent was obtained from patients before interviews could proceed. For illiterate participants written informed consent was obtained from literate legal guardians. Patients were assured of confidentiality of information they provided and that this would have no bearing on the care they would receive at the hospital in future visits. Information obtained from patients was handled by authorized personnel only. All study methods were performed in accordance with MZUNIREC regulations and guidelines.

\section{Consent for publication}

This manuscript does not contain individual person's data and therefore consent for publication was not required

\section{Availability of data and materials}

The datasets used and/or analysed during the current study are available from the corresponding author on reasonable request. Email: kayiraalfred@gmail.com

\section{Competing interests}

The authors declare that they have no competing interests

\section{Funding}

The study was funded by Pingtung Christian Hospital, Taiwan through Luke International Norway (LIN), Malawi, Grant Number: PS-IR-108001. The funder played no role in the design of the study and collection, analysis, and interpretation of data and in writing the manuscript.

\section{Authors' contributions}

FWS conceptualized and designed the study. TJW provided inputs to the manuscript and funding acquisition. PUK, MRC, CSC, BCM, PK and ABK refined the study design and contributed to the development of the study protocol. PUK supervised data collection. FWS, PUK, MRC, BCM and ABK devised the data analysis plan. ABK analysed and interpreted the data, and wrote the manuscript. All authors read and approved the final manuscript.

\section{Acknowledgements}

The authors are sincerely grateful to Pingtung Christian Hospital and Luke International Norway (LIN) for funding this study

\section{References}

1. Quality Management Policy for the Health Sector of Malawi [Internet]. Vol. 1, Quality management policy. 2018 [cited 2021 Aug 7]. Available from: https://www.health.gov.mw/ accessed on 01/11/2020

2. Ministry of Health (2016). Situation Analysis of the Malawi Health Sector.

3. Malawi Ministry of Health and Population. Naonal Health Indicators Handbook for Monitoring Health Sector Performance [Internet]. 2018 [cited 2021 Aug 7]. p. 62-7. Available from: https://www.healthdatacollaborative.org/fileadmin/uploads/hdc/Documents/Country_ documents/Malawi_National_Health_Indicators_FINAL_v11_clean_wt_sign_combo.pdf

4. Risser NL, Batey V. Development of an instrument to measure patient satisfaction with nurses and nursing care in primary care settings. Nurs Res [Internet]. 1975 [cited 2021 Aug 8];24(1):45-52. Available from: https://pubmed.ncbi.nlm.nih.gov/1038021/ 
5. Donabedian A. The Quality of Care: How Can It Be Assessed? JAMA J Am Med Assoc [Internet]. 1988 Sep 23 [cited 2021 Sep 30];260(12):1743-8. Available from: https://jamanetwork.com/journals/jama/fullarticle/374139

6. Arah OA, Roset B, Delnoij DMJ, Klazinga NS, Stronks K. Associations between technical quality of diabetes care and patient experience. Heal Expect [Internet]. 2013 Dec [cited 2021 Aug 9];16(4). Available from: https://pubmed.ncbi.nlm.nih.gov/22066800/

7. Shirley ED, Sanders JO. Measuring quality of care with patient satisfaction scores [Internet]. Vol. 98, Journal of Bone and Joint Surgery - American Volume. J Bone Joint Surg Am; 2016 [cited 2021 Aug 9]. p. e83. Available from: https://pubmed.ncbi.nlm.nih.gov/27707857/

8. Cleary PD, Edgman-Levitan S, Roberts M, Moloney TW, McMullen W, Walker JD, et al. Patients evaluate their hospital care: A national survey. Health Aff. 1991 Jul 24;10(4):254-67.

9. Reid RJ, Coleman K, Johnson EA, Fishman PA, Hsu C, Soman MP, et al. The group health medical home at year two: Cost savings, higher patient satisfaction, and less burnout for providers [Internet]. Vol. 29, Health Affairs. Health Aff (Millwood); 2010 [cited 2021 Aug 2]. p. 835-43. Available from: https://pubmed.ncbi.nlm.nih.gov/20439869/

10. Jenkinson C, Coulter A, Bruster S, Richards N, Chandola T. Patients' experiences and satisfaction with health care: Results of a questionnaire study of specific aspects of care. Qual Saf Heal Care [Internet]. 2002 [cited 2021 Aug 9];11(4):335-9. Available from: https://pubmed.ncbi.nlm.nih.gov/12468693/

11. Christman LP. Increasing Patient Satisfaction: A Guide for Nurses. Nursing Administration Quarterly. Springer Pub. Co; 1996.

12. Pascoe GC. Patient satisfaction in primary health care: A literature review and analysis. Eval Program Plann. 1983 Jan 1;6(3-4):185-210.

13. Narayan KMV, Gregg EW, Fagot-Campagna A, Gary TL, Saaddine JB, Parker C, et al. Relationship between quality of diabetes care and patient satisfaction. J Natl Med Assoc [Internet]. 2003 Jan 1 [cited 2021 Aug 9];95(1):64. Available from: /pmc/articles/PMC2594360/?report=abstract

14. Batbaatar E, Dorjdagva J, Luvsannyam A, Savino MM, Amenta P. Determinants of patient satisfaction: A systematic review [Internet]. Vol. 137, Perspectives in Public Health. Perspect Public Health; 2017 [cited 2021 Aug 9]. p. 89-101. Available from: https://pubmed.ncbi.nlm.nih.gov/27004489/

15. National Statistical Office. 2018 Malawi Population and Housing Census Main Report [Internet]. 2019 [cited 2021 Sep 30]. Available from: http://www.nsomalawi.mw/images/stories/data_on_line/demography/census_2018/2018 Malawi Population and Housing Census Main Report.pdf

16. Government of Malawi. Health Sector Strategic Plan II (2017-2022) [Internet]. 2017 [cited 2021 Oct 1]. p. 122. Available from:

https://extranet.who.int/countryplanningcycles/sites/default/files/planning_cycle_repository/malawi/health_sector_strategic_plan_ii_030417_smt_dps.pc

17. Maseko FC, Chirwa ML, Muula AS. Client satisfaction with cervical cancer screening in Malawi. 2014 [cited 2021 Jul 27 ]; Available from: http://www.biomedcentral.com/1472-6963/14/420

18. Creanga AA, Gullo S, Kuhlmann AKS, Msiska TW, Galavotti C. Is quality of care a key predictor of perinatal health care utilization and patient satisfaction in Malawi? BMC Pregnancy Childbirth [Internet]. 2017 May 22 [cited 2021 Jul 27];17(1). Available from: /pmc/articles/PMC5440969/

19. Changole J, Bandawe C, Makanani B, Nkanaunena K, Taulo F, Malunga E, et al. Patients' satisfaction with reproductive health services at Gogo Chatinkha Maternity Unit, Queen Elizabeth Central Hospital, Blantyre, Malawi. Malawi Med J [Internet]. 2010 [cited 2021 Jul 27];22(1):5. Available from: /pmc/articles/PMC3345683/

20. Chimatiro GL, Rhoda AJ, Wit L De. Stroke patients' outcomes and satisfaction with care at discharge from four referral hospitals in Malawi: A crosssectional descriptive study in limited resource. Malawi Med J [Internet]. 2018 Sep 1 [cited 2021 Jul 27];30(3):152. Available from: /pmc/articles/PMC6307053/

21. Ezegwui, Okoye O, Aghaji A, Okoye O, Oguego N. Patients' satisfaction with eye care services in a Nigerian teaching hospital. Niger J Clin Pract [Internet]. 2014 Sep 1 [cited 2021 Jul 28];17(5):585. Available from: https://www.njcponline.com/article.asp?issn=11193077; year=2014; volume=17;issue=5; spage=585; epage=588; aulast=Ezegwui

22. Ssengooba W, Kirenga B, Muwonge C, Kyaligonza S, Kasozi S, Mugabe F, et al. Patient satisfaction with TB care clinical consultations in Kampala: a cross sectional study. Afr Health Sci [Internet]. 2016 [cited 2021 Jul 28];16(4):1101. Available from: /pmc/articles/PMC5448822/

23. Kasa AS, Gedamu H. Predictors of adult patient satisfaction with nursing care in public hospitals of Amhara region, Northwest Ethiopia. BMC Health Serv Res [Internet]. 2019 Jan 21 [cited 2021 Jul 29];19(1). Available from: /pmc/articles/PMC6341709/

24. Sharew NT, Bizuneh HT, Assefa HK, Habtewold TD. Investigating admitted patients' satisfaction with nursing care at Debre Berhan Referral Hospital in Ethiopia: A cross-sectional study. BMJ Open [Internet]. 2018;8(5):21107. Available from: http://bmjopen.bmj.com/

25. Asamrew N, Endris AA, Tadesse M. Level of Patient Satisfaction with Inpatient Services and Its Determinants: A Study of a Specialized Hospital in Ethiopia [Internet]. Vol. 2020, Journal of Environmental and Public Health. Hindawi Limited; 2020 [cited 2021 Jul 29]. Available from:

/pmc/articles/PMC7443030/

26. Nabbuye-Sekandi J, Makumbi FE, Kasangaki A, Kizza IB, Tugumisirize J, Nshimye E, et al. Patient satisfaction with services in outpatient clinics at Mulago hospital, Uganda. Int J Qual Heal Care [Internet]. 2011 Oct 1 [cited 2021 Jul 29];23(5):516-23. Available from:

https://academic.oup.com/intqhc/article/23/5/516/1864829

27. Mohammed H, Oljira L, Roba KT, Yimer G, Fekadu A, Manyazewal T. Containment of COVID-19 in Ethiopia and implications for tuberculosis care and research [Internet]. Vol. 9, Infectious Diseases of Poverty. BioMed Central; 2020 [cited 2021 Oct 1]. Available from: /pmc/articles/PMC7492795/

28. Ongole JJ, Rossouw TM, Bernard Fourie P, Stoltz AC, Hugo J, Marcus TS. Sustaining essential healthcare in Africa during the COVID-19 pandemic. Vol. 24, International Journal of Tuberculosis and Lung Disease. International Union Against Tuberculosis and Lung Disease (The Union); 2020. p. 643-5.

29. Kwobah EK, Mwangi A, Patel K, Mwogi T, Kiptoo R, Atwoli L. Mental Disorders Among Health Care Workers at the Early Phase of COVID-19 Pandemic in Kenya; Findings of an Online Descriptive Survey. Front Psychiatry. 2021 Jul 22;12.

30. Htay MNN, Marzo RR, AlRifai A, Kamberi F, Radwa Abdullah EA, Nyamache JM, et al. Immediate impact of COVID-19 on mental health and its associated factors among healthcare workers: A global perspective across 31 countries. J Glob Health [Internet]. 2020 Dec 1 [cited 2021 Oct 1];10(2):1-6. Available 
from: https://pubmed.ncbi.nlm.nih.gov/33214890/

31. Sharma A, Gupta P, Jha R. COVID-19: Impact on Health Supply Chain and Lessons to Be Learnt. J Health Manag. 2020 Jun 1;22(2):248-61.

32. Ranney ML, Griffeth V, Jha AK. Critical Supply Shortages - The Need for Ventilators and Personal Protective Equipment during the Covid-19 Pandemic. N Engl J Med. 2020 Apr 30;382(18):e41.

33. Medinilla A, Byiers B, Apiko P. African regional responses to COVID-19 [Internet]. 2020 [cited 2021 Oct 2]. Available from: www.ecdpm.org/dp272 